\title{
EFFECT OF GREEN TEA EXTRACT ON MODULATING THE ANTIBACTERIAL ACTIVITY OF STANDARD ANTIBIOTICS AGAINST THE CLINICAL ISOLATES OF Acinetobacter baumannii
}

\section{Yuyun Sri Wahyuni ${ }^{1,2}$, Firzan Nainu ${ }^{3}$, Sartini Sartini ${ }^{3, *}$}

\author{
${ }^{1}$ Magister Student at Faculty of Pharmacy Hasanuddin University \\ ${ }^{2}$ Yamasi Pharmacy Academic Makassar, Indonesia \\ ${ }^{3}$ Faculty of Pharmacy, Hasanuddin University Kampus UNHAS Tamalanrea Km.10, Makassar 90245 Indonesia \\ Received - December 20, 2020; Revision - March 19, 2021; Accepted - April 25, 2021 \\ Available Online - September 08, 2021
}

DOI: http://dx.doi.org/10.18006/2021.9(Spl-2-ICOPMES_2020).S202.S207

KEYWORDS
Green Tea
Acinetobacter baumannii
Modibiotic resistance
Modor

\begin{abstract}
Most of the clinical isolates of Acinetobacter baumannii are found resistant to the $\beta$-lactam antibiotics. This research aimed to determine the ability of green tea extract in modulating the antibacterial activity of standard antibiotics amoxicillin, cefotaxime, and imipenem against the clinical isolates of $A$. baumannii. The clinical isolates used in this study were collected from the Laboratory of Clinical Pathology, Wahidin Sudiro Husodo Hospital Makassar, Indonesia. To determine whether the bacterial isolate is resistant, the experiment was carried out using disk agar diffusion and Vitek-2 methods. Further, the antibacterial activity of the green tea, selected antibiotics, and their combination was determined by using a checkerboard microdilution assay. Results of the study revealed that among the selected two clinical isolates one of the A. baumannii isolates was found resistant to selected standard amoxicillin-clavulanate, cefotaxime, and imipenem, while the other one was found sensitive. Further, green tea extract with a concentration of up to $1.2 \mathrm{mg} / \mathrm{ml}$ didn't have any significant effect on the inhibition of A. baumannii growth. Similarly, at the same concentration $(1.2 \mathrm{mg} / \mathrm{ml})$ no modulation effect of green tea extract was reported on the antibacterial activity of amoxicillin, cefotaxime, and imipenem against the $A$. baumannii isolates.
\end{abstract}

* Corresponding author

E-mail: sardj@farmasi.unhas.ac.id (Sartini)

Peer review under responsibility of Journal of Experimental Biology and Agricultural Sciences.

Production and Hosting by Horizon Publisher India [HPI] (http://www.horizonpublisherindia.in/).

All rights reserved.
All the articles published by Journal of Experimental Biology and Agricultural Sciences are licensed under a Creative Commons Attribution-NonCommercial 4.0 International License Based on a work at www.jebas.org.

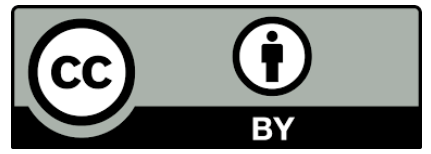




\section{Introduction}

Now a day's antibiotic resistance problems have emerged as a most serious threat which is challenging researchers, and health professionals in search of new treatments or push them for modification in medical intervention. Currently, inappropriate use of antibiotics, genetic mutation, and other protective mechanisms such as the formation of persister cells have been mainly linked to a large number of antibiotic resistance to pathogenic bacteria (Alnimr et al., 2020). Currently, Acinetobacter baumannii, a nosocomial pathogen, and gramnegative coccobacillus bacteria has been reported as a resistant strain to several $\beta$-lactam antibiotics, and occasionally it converted to multidrug or pan-drug strains (Prashanth \& Badrinath, 2004; Gustawan et al., 2014; Mayasari \& Siregar, 2015; Alnimr et al., 2020; Abdi et al., 2020).

In addition, the prevalence of A.baumannii was moderately found, but the occurrence of resistance cases is high. Gustawan et al. (2014) found that about 23 bacterial isolated from infected pediatric patients were notably classified as multidrugresistant (MDR) to aminoglycoside, carbapenem, quinolone, cephalosporin, penicillin, $\beta$-lactamase inhibitors, and tigesicline groups. This paramount pathogen in clinical terms, particularly in hospital-acquired infections requires the search for new antibiotics. The search for new antibiotics takes a long time and high-cost demand. Instead of trying to search for a combination of antibiotic regimens, screening for the active compound from plants that can modulate the antibacterial activity of existing antibiotics could be an alternative way (Chambers et al., 2019).

According to Osterburg et al. (2009), epigallocathechin-3- gallate (EGCG) from green tea was able to inhibit A. baumannii with a minimum inhibitory concentration (MIC) of 78 to $625 \mu \mathrm{g} / \mathrm{mL}$, while the results of Betts \& Wareham (2014) suggested slightly higher MIC of EGCG against the same bacteria (128 - 1024 $\mu \mathrm{g} / \mathrm{mL}$ ). Other studies have also shown the synergistic effect of epigallocatechin gallate with carbapenem antibiotics on $A$. baumannii (Lee et al., 2017). The green tea extract in water or hydro alcohol is rich in catechins and caffeine alkaloids (PervaUzunalić et al., 2006; Hu et al., 2016). Therefore, green tea extract has various other natural substances which had been claimed to affect several antibiotic activities. Previous researchers found the effect of green tea extract against several microorganisms in line with its synergistic properties with antibiotics (Bazzaz et al., 2016; Lee et al., 2017). The current study was carried out to evaluate the synergistic effect of green tea water extracts with the standard antibiotics amoxicillin, cefotaxime, or imipenem against clinical isolate of A.baumannii.

\section{Materials and Methods}

\subsection{Materials}

A. baumannii isolates were collected in 2019 from the Laboratory of Clinical Pathology Wahidin Sudiro Husodo Hospital, Indonesia. For culturing the collected bacterial isolates Brain Heart Infusion Broth (BHIB), and Muller Hinton Agar (MHA) media (Merck) was used. In other materials, Vitek-2 compact (bioMe'rieux), green tea water extract (collection of Laboratory of Microbiology, Faculty of Pharmacy, UNHAS), 96-well plate, standard antibiotic disc (Oxoid), 0.5 Mc Farland (HiMedia), and Tetrazolium Chloride (Merck) was also used during the current study.

\subsection{Methods}

\subsubsection{Susceptibility assay by agar diffusion method}

Two clinical isolates of A. baumannii were collected in 2019 from the sputum of ICU patients admitted to the Wahidin Sudiro Husodo Hospital, Makassar, Indonesia. Ten microliters of $A$. baumannii bacterial suspension equivalent to 0.5 McFarland solution $\left(10^{8} \mathrm{CFU} / \mathrm{ml}\right)$ was inoculated on the MHA media by the spread plate method. After that, a disc of selected antibiotics were placed on the media and incubated for 24 hours at $37^{\circ} \mathrm{C}$. Bacterial isolates were tested for sensitivity using various classes of antibiotics, including penicillin (amoxicillin-clavulanate), cephalosporin (cefotaxime, ceftazidime, cefazoline, ceftriaxone), and carbapenem (imipenem, meripenem, doripenem).

\subsubsection{Susceptibility assay by Vitek-2 method}

A sterile tube containing $0.45 \%$ saline buffer was inoculated with $145 \mu 1$ of A.baumannii isolate which is equivalent to $0.5 \%$ McFarland turbidity, AST GN/cassette was put into each of these tubes and then inserted into the Vitek-2 compact device.

\subsubsection{Determination of total phenolic content of green tea water extracts using Folin-Ciocalteu method}

Ten milligrams of the green tea extract was dissolved in $25 \mathrm{ml}$ of analytical grade methanol. Similarly, gallic acid was also dissolved in the methanol and made a series of dilutions, $1 \mathrm{ml}$ of each test solution and standard solution were added with $5 \mathrm{ml}$ of Folinciocalteu ( $7.5 \%$ solution). The mixture was let stand for 8 minutes, and this was followed by adding $4 \mathrm{ml}$ of $1 \% \mathrm{NaOH}$ and incubates for 1 hour. Measurement of the absorption of each solution was conducted at a wavelength of approximately $730 \mathrm{~mm}$. Test the blank was measured in the same way without the addition of test solutions. The calibration curve was prepared and the equivalent concentrations were calculated (Sartini et al., 2019). 
2.2.4 Determination of epigallocatechin-3-gallate (EGCG) content by using ultra-fast liquid chromatography

The tea extract was dissolved in methanol until a concentration of 10 ppm was obtained. EGCG concentration analysis was performed by pro-liquid chromatography having Shim-pack Vp-ods column (UFLC Simadzu), and phosphate buffer ( $\mathrm{pH}$ 5): acetonitrile (95.5\% $\mathrm{v} / \mathrm{v}$ ) used as a mobile phase. The injection volume was $20 \mu \mathrm{l}$ and the flow rate was $1 \mathrm{ml} /$ minute (Sartini et al., 2019).

2.2.5 Synergy test of green tea extract using the checkerboard microdilution assay method

Ten microliters of antibiotic solution and $10 \mu \mathrm{l}$ of green tea extract were inserted into sterile 96-well plates with a dilution factor of 1 : 2 , the concentration of green tea extract was $12 \mathrm{mg} / \mathrm{ml}$, while in the case of standard antibiotic amoxicillin, cefotaxime, and imipenem this concentration was $2 \mathrm{mg} / \mathrm{ml}, 0.5 \mathrm{mg} / \mathrm{ml}$, and $0.25 \mathrm{mg} / \mathrm{ml}$ respectively. This was followed by the addition of $178 \mu \mathrm{l}$ of BHIB media, and $2 \mu \mathrm{l}$ of the test bacteria to each well. The plate was incubated for 24 hours at $37^{\circ} \mathrm{C}$. After incubation, $10 \mu \mathrm{l}$ of $0.1 \%$ TTC solution was added and incubated for 30 minutes at room temperature. The lowest concentration that shows the absence of bacterial growth (marked by the absence of changes in the color of the media to pink/red) is the minimum inhibitory concentration of the sample. If the color that arises is not clear, because of the color of the extract, it is etched onto the BHIB media so that it is sterile and re-incubated for 24 hours for the confirmation test.

\subsection{Statistical Analysis}

Two-way analysis of variance (ANOVA $\mathrm{p}<0.05$ ) was applied to subjugate data in the form of Mean \pm SEM (Standard Error of Mean).

\section{Results and Discussion}

\subsection{Total phenolic and EGCG content of green tea extract} (GTE)

Previous studies suggested that the green tea polyphenolic compounds contributed as antibacterial and modulator compounds in association with some antibiotics against various bacteria. Green tea contains various polyphenols catechin including Epigallocatechin-3-gallate (EGCG) which has antibiotic properties. The results of the current study showed that the green tea water extract contained a total polyphenol of $508.5+5.4 \mathrm{mg}$ gallic acid equivalent/g extract and EGCG content of $340.7+20.4 \mathrm{mg} / \mathrm{g}$ extract), which is around $66.9 \%$ of the total polyphenols. The high value of total polyphenol content obtained in this study might be due to the extraction procedure in which extraction was carried out with the aid of high pressure. Xi et al. (2015) suggested that the green tea extraction carried out with the help of high pressure (450 Mpa) yielded higher total phenolic compounds than the conventional extraction methods.

\subsection{Susceptibility assay of $A$. baumannii clinical isolates}

The antibiotic susceptibility of both the clinical isolates collected from the Laboratory of Clinical Pathology, Wahidin Sudiro Husodo Hospital, Makassar was tested against the selected antibiotics by disc diffusion and Vitek-2 methods (Table $1 \& 2$ ). Results presented in table 1 and 2 have been shown that $A$. baumannii isolate 231/07 has been resistant to amoxicillinclavulanate antibiotics, some cephalosporin groups, and carbapenem groups, while A. baumannii isolate 288/05 has a sensitivity to some carbapenem (imipenem, meropenem, doripenem) and relatively sensitive to some cephalosporins. Similar results were reported by Lin \& Lan (2014), these researchers found that several isolates of A. baumannii were resistant to most of the antibiotics, including the carbapenem group. According to Xioa et al. (2016), the causes of carbapenem (imipenem) resistance in A. baumannii might be the presence of $\beta$ lactamase genes such as blaKPC, blaIMP, blaOXA-24, blaOXA 58 , blaSHV, blaGIM; these genes are involved in efflux pumps and mutations in protein-coding genes. Further, Badave \& Kulkarni (2015) reported that $62.5 \%$ of 72 clinical isolates produced biofilm which might be associated with the multiple drug resistance in A.baumannii.

Table 1 Antibiotic susceptibility of A. baumannii isolates against selected antibiotics by using disc diffusion method

\begin{tabular}{|cccccccc|}
\hline & & \multicolumn{3}{c|}{$\begin{array}{c}\text { Diameter of inhibitory zone (mm) } \\
\text { Cephalosporin }\end{array}$} & \multicolumn{3}{c|}{ Carbapenem } \\
\hline & Penicillin & CAZ & CRO & CTX & CZ & MEM & IMI \\
\hline $231 / 07$ & AMC & $8 \mathrm{R}$ & $8 \mathrm{R}$ & $8 \mathrm{R}$ & $8 \mathrm{R}$ & $8 \mathrm{R}$ & $11 \mathrm{R}$ \\
\hline $288 / 05$ & $8 \mathrm{R}$ & $25 \mathrm{~S}$ & $20 \mathrm{I}$ & $18 \mathrm{I}$ & $8 \mathrm{R}$ & $18 \mathrm{~S}$ & $35 \mathrm{~S}$ \\
\hline
\end{tabular}

AMC $=$ Amoxicillin-clavulanate $(20 / 10 \mu \mathrm{g}) ; \mathrm{CTX}=$ Cefotaxime $(30 \mu \mathrm{g}) ; \quad \mathrm{CAZ}=$ Ceftazidime $(30 \mu \mathrm{g}) ; \mathrm{CZ}=\mathrm{Cefazoline}(30 \mu \mathrm{g}) ;$ $\mathrm{IMI}=$ Imipenem $(10 \mu \mathrm{g}) ; \mathrm{MEM}=$ Meropenem $(10 \mu \mathrm{g}) ; \mathrm{S}=$ Sensitive, $\mathrm{I}=$ Intermediate, $\mathrm{R}=$ Resistant

Table 2 Antibiotic susceptibility of A. baumannii isolates against selected antibiotics by using Vitek-2 method

\begin{tabular}{|ccc|ccccc} 
& \multicolumn{4}{c}{} & \multicolumn{4}{c}{ MIC values (ppm) using Vitek-2 method } \\
Isolate code & AMC & CTX & CRO & CAZ & IMI & MEM & DORI \\
\hline $231 / 07$ & nd & $\geq 64 \mathrm{R}$ & $\geq 64 \mathrm{R}$ & $\geq 64 \mathrm{R}$ & $\geq 16 \mathrm{R}$ & $\geq 16 \mathrm{R}$ \\
\hline $288 / 05$ & nd & $8 \mathrm{~S}$ & $16 \mathrm{I}$ & $4 \mathrm{~S}$ & $\leq 0.25 \mathrm{~S}$ & $\leq 0.25 \mathrm{~S}$ \\
\hline
\end{tabular}

AMC = Amoxicillin-clavulanate CTX = Cefotaxime; CAZ = Ceftazidime $;$ CRO = ceftri-axone; IMI = Imipenem; MEM = Meropenem

DORI = Doripenem; $\mathrm{nd}=$ no detection; $\mathrm{S}=$ Sensitive, $\mathrm{I}=$ Intermediate, $\mathrm{R}=$ Resistant 
3.3 Synergistic effect of green tea extract along with selected antibiotics

The synergistic effect of green tea extract with three antibiotics viz., amoxicillin, cefotaxime, and imipenem were tested by checker board microdilution assay and the results are presented in table 3 \& figure 1 .

Based on the data given in table 3, the green tea extract has the least inhibitory effect on both clinical isolates of A. baumannii and found minimum inhibitory levels of $1.2 \mathrm{mg} / \mathrm{ml}$ which suggested that the green tea extract is not effective in inhibiting the growth of these bacteria. Some differences are reported in the MIC value given in table 2 and 3, this might be due to the different methods used for the estimation of MIC, in table 2 results of Vitek-2 rapid method was given which is more sensitive than the microdilution method (table 2).

The MICs of amoxicillin, cefotaxime, and imipenem showed that the antibiotics have experienced resistance against the clinical isolates. In the case of synergistic effect, no modulation effect of the green tea extract was reported on the antibacterial activities of the selected antibiotics. The previous study of Jung \& Park (2015) have been reported MDR Acinetobacter which has resistance against the penicillin, cephalosporin, fluoroquinone, and aminoglycoside groups, and no plant extracts have been found that can increase the antibiotic activity of these antibiotics against MDR A.baumannii. While the results of Lee et al. (2017) are contradictory to the findings of the current study and these researchers reported that the EGCG had a synergistic effect against A. baumannii with carbapenem antibiotics. Epicatechin is an important component of green tea extract which is responsible for the antibacterial activities of green tea but according to Betts et al. (2017), it is required in a minimum concentration of $1024-2048$ ppm for bacterial growth inhibition. In contrast to this, Sartini et al. (2020) reported that at $75 \mathrm{ppm}$ GTE the antibacterial activity of amoxicillin increased by 32 fold as compared to the $8 \mathrm{ppm}$ to 25 ppm concentration. The poor synergistic effect of EGCG reported in the current study might be due to the less concentration of the green tea extract. Research by Bazzaz et al. (2016) also states that the combination of methylxanthine and some antibiotics are antagonistic to some pathogenic bacteria. Further, Bazzas et al. (2018) suggested that the type of bacterial strains also plays an important role in determining the efficacy of the methylxanthine and antibiotic gentamycin combination, because several strains of Staphylococcus aureus and Escherichia coli have different synergistic and non-synergistic effects against this combination.

Table 3 MIC (mg/ml) values of green tea extract, antibiotics, and combination of antibiotics with green tea extract

\begin{tabular}{|ccc|}
\hline Test Sample & MIC (mg/ml) \\
\hline & A. baumannii isolate 288/05 & A. baumannii isolate 231/07 \\
\hline Green Tea Extract (GTE) & $>1.2$ & $>1.2$ \\
\hline Amoxicillin & $>0.2$ & $>0.2$ \\
\hline Cefotaxime & $>0.05$ & 0.0125 \\
\hline Imipenem & 0.025 & 0.025 \\
\hline Amoxicillin + GTE & $>0.2$ & $>0.2$ \\
\hline Cefotaxim +GTE & $>0.05$ & $>0.05$ \\
\hline Imipenem +GTE & 0.025 & 0.025 \\
\hline
\end{tabular}

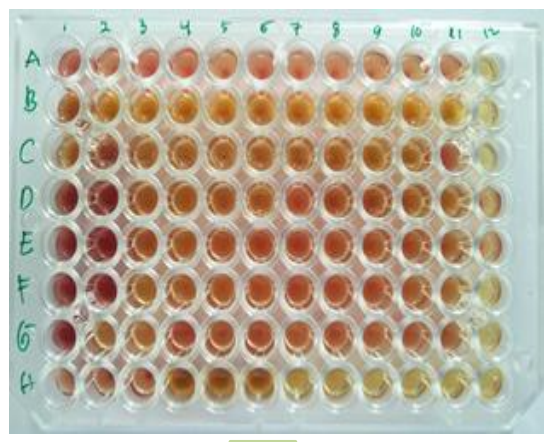

A

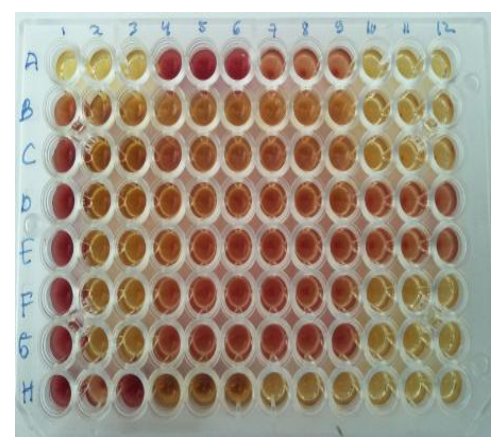

C

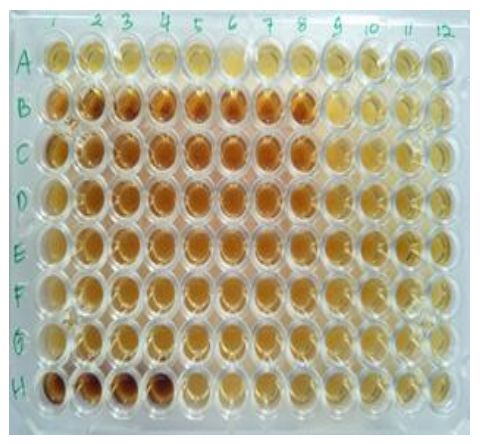

I

Figure 1 Evaluation of antibiotic sensitivity by checkerboard microdilution assay in 96-well microtiter plate; here Column 1 (B-G): concentration of GTE $(1.2-0.004) \mathrm{mg} / \mathrm{ml}$; Line A (1-11): cocentration of amoxicillin $(0.2-0.002) \mathrm{mg} / \mathrm{ml}$; cefotaxime $(0.5-0.0002)$ $\mathrm{mg} / \mathrm{ml}$; imipenem $(0.25-0.0003) \mathrm{mg} / \mathrm{ml}$; plate $\mathrm{A}=$ amoxicillin $-\mathrm{GTE}$, plate $\mathrm{C}=$ Cefotaxime-GTE, plate $\mathrm{I}=\mathrm{Imipenem}-\mathrm{GTE}$ 


\section{Conclusion}

Results of the study can be concluded that the water extract of green tea did not have any significant effect on the increasing antibacterial activity of amoxicillin, cefotaxime, and imipenem against the selected clinical isolates of A.baumannii. Further research is needed to establish the required concentration and combination of green tea extract against $A$. baumannii isolates.

\section{Acknowledgment}

Thank for the Research Grant for Magister Student from Indonesian Ministry of Research, Technology, and Higher Education with no. 2759/UN /421/KU0201/19

\section{Conflict of Interest}

No conflict of interest in this research

\section{Reference}

Abdi SN, Ghotaslou R, Ganbarov K, Mobed A, Tanomand A, Yousefi M, et al. (2020) Acinetobacter baumannii efflux pumps and antibiotic resistance. Infection and drug resistance 13: 423.

Alnimr A, Alamri A, Alsultan A (2020) Genetic Diversity of Imipenem-Resistant Acinetobacter baumannii Infections at an Intensive Care Unit. Critical care Research and Practice 2020. doi $10.1155 / 2020 / 3290316$.

Badave GK, Kulkarni D (2015) Biofilm producing multidrug resistant Acinetobacter baumannii: an emerging challenge. Journal of Clinical and Diagnostic Research 9(1): DC08-DC10.

Bazzaz BSF, Khameneh B, Ostad MRZ, Hosseinzadeh H (2018) In vitro evaluation of antibacterial activity of verbascoside, lemon verbena extract and caffeine in combination with gentamicin against drug-resistant Staphylococcus aureus and Escherichia coli clinical isolates. Avicenna Journal of Phytomedicine 8(3): 246.

Bazzaz BSF, Sarabandi S, Khameneh B, Hosseinzadeh H (2016) Effect of Catechins, greentea extract and Methylxanthines in combination with gentamicin against Staphylococcus aureus and Pseudomonas aeruginosa combination therapy against resistant bacteria. Journal of Pharmacopuncture 19(4): 312.

Betts JW, Hornsey M, Wareham DW, La Ragione RM(2017) In vitro and in vivo activity of theaflavin-epicatechin combinations versus multidrug-resistant Acinetobacter baumannii.Infectious Diseases and Therapy 6(3): 435-442.

Betts JW, Wareham DW (2014) In vitro activity of curcumin in combination with epigallocatechin gallate (EGCG) versus multidrug-resistant Acinetobacter baumannii. BMC Microbiology 14(1): 172 .
Chambers CS, Viktorová J, Řehořová K, Biedermann D, Turková L, Macek T, et al. (2019) Defying multidrug resistance! Modulation of related transporters by flavonoids and flavonolignans. Journal of Agricultural and Food Chemistry 68 (7): 1763-1779.

Gustawan IW, Satari HI, Amir I, Astrawinata DA (2014) Gambaran Infeksi Acinetobacter baumannii dan Pola Sensitifitasnyater hadap Antibiotik. Sari Pediatri 16(1): 35-40.

Hu CJ, GaoY, Liu Y, Zheng XQ, Ye JH, Liang YR, Lu JL (2016) Studies on the mechanism of efficient extraction of tea components by aqueous ethanol. Food Chemistry 194: 312-318.

Jung J, Park W (2015) Acinetobacter species as model microorganisms in environmental microbiology: current state and perspectives. Applied Microbiology and Biotechnology 99(6): 2533-2548.

Lee S, Al Razqan GS, Kwon DH (2017) Antibacterial activity of epigallocatechin-3-gallate (EGCG) and its synergism with $\beta$ lactam antibiotics sensitizing carbapenem-associated multidrug resistant clinical isolates of Acinetobacter baumannii. Phytomedicine 24: 49-55.

Lin MF, Lan CY (2014) Antimicrobial resistance in Acinetobacter baumannii: From bench to bedside. World Journal of Clinical cases 2(12):787-814. doi:10.12998/wjcc.v2.i12.787.

Mayasari E, Siregar C (2015) Prevalence of Acinetobacter baumannii isolated from clinical specimens in Adam Malik Hospital. Majalah Kedokteran Andalas 37(1): 1-7.

Osterburg A, Gardner J, Hyon SH, Neely A, Babcock G (2009) Highly antibiotic-resistant Acinetobacter baumannii clinical isolates are killed by the green tea polyphenol (-)-epigallocatechin3-gallate (EGCG). Clinical Microbiology and Infection 15(4): 341346.

Perva-Uzunalić A, Škerget M, Knez Ž, Weinreich B, Otto F, Grüner S (2006) Extraction of active ingredients from green tea (Camellia sinensis): Extraction efficiency of major catechins and caffeine. Food Chemistry 96(4): 597-605.

Prashanth K, Badrinath S (2004) In vitro susceptibility pattern of Acinetobacter species to commonly used cephalosporins, quinolones, and aminoglycosides. Indian Journal of Medical Microbiology 22(2): 97-103.

Sartini S, Djide MN, Amir MN, Permana AD (2020) Phenolic-rich green tea extract increases the antibacterial activity of amoxicillin against Staphylococcus aureus by in vitro and ex vivo studies. Journal of Pharmacy \& Pharmacognosy Research 8(6): 491-500. 
Sartini S, Djide MN, Nainu F (2019) Correlation Phenolic Concentration to Antioxidant and Antibacterial Activities of Several Ethanolic extracts from Indonesia. Journal of Physics: IOP Conference SeriesPublishing1341 (7): 072009.

Xi J, He L, Yan L (2015) Kinetic modeling of pressureassisted solvent extraction of polyphenols from green tea in comparison with the conventional extraction. Food Chemistry 166: 287-291.

Xiao SZ, Chu HQ, Han LZ, Zhang ZM, Li B, Zhao L, Xu L (2016) Resistant mechanisms and molecular epidemiology of imipenemresistant Acinetobacter baumannii. Molecular Medicine Reports 14(3): 2483-2488. 